\title{
Investigation of Audio-Visual Simple Reaction Time of University Athletes and Non-Athletes
}

\author{
Md. Hamidur Rahman ${ }^{1 *}$, Muhammad Shahidul Islam² \\ ${ }^{1}$ Assistant Professor, Department of Physical Education and Sports Science, Jashore University of Science and Technology, Jashore, \\ Bangladesh \\ ${ }^{2}$ Research Scholar, Department of Physical Education and Sport Science, Visva-Bharati University, Santiniketan, West Bengal, India
}

DOI: $10.36348 /$ jaspe.2021.v04i03.002

| Received: 25.02.2021 | Accepted: 09.03.2021 | Published: 10.03.2021

*Corresponding author: Md. Hamidur Rahman

Email: hamid.just@yahoo.com

\section{Abstract}

Reaction time (RT) is a true pointer of eye-hand coordination, response, and alertness of a person. In sports and daily life, the majority of work is done by the use of auditory and visual information. RT is a measurement of how quickly the particular tasks are done. The purpose of this study was to investigate auditory and visual simple reaction time of university male team branch athletes (basketball, handball, volleyball, football, and cricket) and non-athletes. Totally forty (40) subjects randomly participated in this study; among them $(n=20)$ were team branch athletes and the rest $(n=20)$ non-athletes. Audio-Visual Reaction Timer (AVRT) was used to collect auditory reaction time (ART) and visual reaction time (VRT) data. Ten values of ART and VRT of dominant and non-dominant hands were recorded. Excluding the two fastest and slowest values, and the average for the middle six values saved as two digits of milliseconds were RT data. Descriptive statistics- mean, SD, and Inferential statistics- dependent and independent t-test was applied to check the level of significance $(\mathrm{p}<0.05$ and $\mathrm{p}<0.01)$. Paired sample t-test of university athletes and non-athletes ART was statistically significant than that of VRT $(\mathrm{p}<0.01)$. A significant difference was found of ART and VRT between dominant and non-dominant hands of both groups together $(\mathrm{p}<0.01)$. Independent t-test of ART and VRT of dominant and non-dominant hands between athletes and non-athletes was statistically significant $(\mathrm{p}<0.05)$. In summary, it can be said that in athletes and non-athletes groups auditory reaction time (ART) was faster than the visual reaction time (VRT) and considering both the groups together, the dominant hand was superior to the non-dominant hand in quickness. However, ART and VRT of dominant and non-dominant hands of university athletes took the upper hand over the nonathletes group.

Keywords: Audio-Visual Reaction Time, Athletes and Non-Athletes, Handedness, Hemisphere.

Copyright ( $) 2021$ The Author(s): This is an open-access article distributed under the terms of the Creative Commons Attribution 4.0 International License (CC BY-NC 4.0) which permits unrestricted use, distribution, and reproduction in any medium for non-commercial use provided the original author and source are credited.

\section{INTRODUCTION}

The deliberate voluntary response to many stimuli such as auditory, visual, and tactile stimuli is the reaction [1]. Reaction time (RT) describes the time interval between an external signal and response to it. RT measures how faster an organ can reply to a special stimulus [2]. RT can be described into three types; simple reaction time (SRT), recognition reaction time (RRT), and choice reaction time (CRT) [3]. In the year 1865 Franciscus C. Donders, was the first scientist to measure reaction time in the laboratory and noticed that simple reaction time is faster than the recognition reaction time and that the choice reaction time is the longest to simple and recognition reaction time [4]. RT is composed of the start of eye movements, eye movement time, decision time, and muscle contraction time [5]. SRT refers to reacting to a single stimulus and is usually very fast [6].

Physiological and pharmacological factors affected reaction time [7, 8]. In simple RT, stimuli considering the fastest reaction time to the lower one are- tactile (90-180 ms), auditory (120-180 ms), and visual (150-200 ms) stimuli respectively [9]. Youth sedentary perform faster visual and auditory reaction time with growing age between 11-18 years [10]. According to gender, visual and auditory RT was significantly different in males and females, and males have faster reaction times than females for both auditory as well as visual stimuli [11]. Physical exercises $[12,13]$ affect the visual and auditory reaction 
Md. Hamidur Rahman \& Muhammad Shahidul Islam., J Adv Sport Phys Edu, Mar, 2021; 4(3): 24-29

time of volleyball players when it is measured at the beginning and the end of the training schedule and it is concluded that VRT and ART decrease by exercise [14]. The right and left hemispheres of the brain function are based on the contralateral theory. The left finger of visual and auditory response time was significantly longer than the right finger in simple and choice reaction time tasks [15].

Many studies have been undertaken to investigate and compare RT and its significance in sport. RT is the key factor of success in many sporting competitions. Quick RT is important for daily activities, alertness, and overall wellness as well. For this reason, RT is a meaningful part of an athlete's daily life and sports performance. An athlete who has better reaction time is more significant than another athlete; has equal neuromuscular mechanisms, cognitive ability, and tactical capacity [16, 17]. Researchers [18] show that physically fit athletes are to have better reaction time than others. Further study demonstrated that athletes have better reaction times compared to non-athletes [19]. Elite athletes had shorter reaction time than nonathletes and also participation in sports reduced reaction time [20].

In games and sports, the visual and auditory stimulus is the use of vision (seeing signals and thinking in images) and audition (using sounds and voices) [21]. Auditory stimuli use sound to send and receive information such as vocal (spoken speech) for verbal and tone of voice, talk speed, volume of speech, and intonation for nonverbal communication. Visual involves signal language that can be seen [22]. It may include body gestures, postures, facial expressions, physical appearance, and movement with change of direction [22-24]. Quick reaction time in team branches athletes communicates their teammate during competition by effective way of sounds and signals.

In daily life majority of work is done by the use of auditory and visual information. In many situations, students experience simple reaction time and become able to quickly adjust to suddenly changing situations. In the Bangladesh context, participation in sports, the concept of physical fitness, and a healthy lifestyle among university students are rapidly increasing [25]. Mental and physical relaxation increase if stretching and flexibility exercises are performed regularly [26].

In the context of the Bangladeshi athlete and non-athlete, present researchers found a research gap to investigate the simple reaction time of auditory and visual reaction time. The purpose of the present study was to examine the simple reaction time of auditory and visual reaction time and to compare athletes and nonathletes of this behavior-based on dominant (preferred) and non-dominant (non-preferred) hand.

\section{MATERIALS AND METHODS}

Forty (40) university male students were randomly selected as subjects (Here 'subject' refers to the persons participating in the research); among them twenty (20) athletes in different sports branches (basketball, handball, volleyball, football, and cricket) and the rest twenty (20) were non-athletes. All athletes were competing at junior national and inter-university levels in their respected sport. The age of the subjects ranging from 17 to 24 years of age (athletes and nonathletes mean age $22.10 \pm 1.65,21.15 \pm 1.39$ years respectively) and data were collected in Jashore University of Science and Technology, Jashore, Bangladesh. All subjects were right-handed and they voluntarily participated in this present study.

Audio-Visual Reaction Timer (AVRT) [27] QMS is certified with ISO 9001:2015 standards was used to collect auditory reaction time (ART) and visual reaction time (VRT) data. AVRT was kept on the table, and the test administrator sat on the operator side and the subjects are trainer side. From a sitting position, the subjects kept both hands on the table and their preferred finger in contact with the AVR timer switch. VRT was recorded by illuminating bulbs, and ART was listening to the sound which served as individual stimuli. VRT and ART were tested for both the dominant and nondominant hands. In both tests, the researchers gave light and sound stimulus 1-3 seconds after the ready call. The subjects were instructed to respond the action and turn off the switch immediately in the shortest time. All subjects repeatedly performed the same tasks 10 times excluding the two fastest and the two slowest values. The average score was considered as the experimented reaction time data. First, two digits of milliseconds (ms) were considered for the study. The test sequence was VRT, then ART of dominant and non-dominant hands. ART and VRT were measured in a quiet and noise-free gymnasium.

The scholar scanned data with the ShapiroWilk test and a normal distribution was found. The data were analyzed using descriptive statistics, mean and standard deviation (SD). An inferential statistics-paired and independent t-test was applied to check the level of significance. The significance level was set at $\mathrm{p}<0.05$ and $\mathrm{p}<0.01$. 


\section{RESULTS}

Table-1: Comparison between ART and VRT of athletes and non-athletes

\begin{tabular}{|l|l|l|l|l|l|l|}
\hline \multirow{2}{*}{ Group } & \multirow{2}{*}{ Parameter } & \multicolumn{2}{|l|}{ Descriptive } & \multicolumn{3}{|l|}{ Inferential: Paired sample t-test } \\
\cline { 3 - 7 } & & Mean $(\mathrm{ms})$ & SD $(\mathrm{ms})$ & t & df & Sig. (2-tailed) \\
\hline \multirow{2}{*}{ Athletes } & ART & 15.25 & 1.80 & \multirow{2}{*}{$5.85^{* *}$} & \multirow{2}{*}{19} & \multirow{2}{*}{0.000} \\
\cline { 2 - 7 } & VRT & 18.05 & 1.64 & & \\
\hline \multirow{2}{*}{ Non-athletes } & ART & 16.65 & 1.69 & \multirow{2}{*}{$4.54^{* *}$} & \multirow{2}{*}{19} & \multirow{2}{*}{0.000} \\
\cline { 2 - 4 } & VRT & 19.25 & 1.71 & &
\end{tabular}

Significance level at $19 \mathrm{df}$ at $* 0.05$ level $=2.093$ and at $* * 0.01$ level $=2.861$

Table: 1 of comparison between ART and VRT of university athletes and non-athletes shows that athletes group ART mean $=15.25 \mathrm{~ms}$ and $\mathrm{SD}=1.80$ $\mathrm{ms}$, on the other hand VRT mean $=18.05 \mathrm{~ms}$ and $\mathrm{SD}=$ $1.64 \mathrm{~ms}, \mathrm{t}_{(19)}=5.85$ and $\mathrm{p}=0.000,(2$-tailed); whereas, in the non-athletes ART mean $=16.65 \mathrm{~ms}$ and $\mathrm{SD}=1.69$ $\mathrm{ms}$, other side VRT mean $=19.25 \mathrm{~ms}$ and $\mathrm{SD}=1.71$ $\mathrm{ms} ; \mathrm{t}_{(19)}=4.54$ and $\mathrm{p}=0.000$, (2-tailed). Both are statistically significant as tabulated value of $\mathrm{t}(0.01)(19)$ $=2.861 \& \mathrm{p}<0.01$. The result shows that athletes and non-athletes groups ART was significantly lower than that of VRT and in both groups ART was faster than the VRT.

Table-2: Paired t-test of ART and VRT between hands of athletes and non-athletes

\begin{tabular}{|c|c|c|c|c|c|c|}
\hline \multirow{2}{*}{\multicolumn{2}{|c|}{ Parameter }} & \multicolumn{2}{|l|}{ Descriptive } & \multicolumn{3}{|c|}{ Inferential: Paired sample t-test } \\
\hline & & \multirow{2}{*}{$\begin{array}{l}\text { Mean (ms) } \\
15.95\end{array}$} & \multirow{2}{*}{$\begin{array}{l}\text { SD (ms) } \\
1.87\end{array}$} & \multirow{3}{*}{$\begin{array}{l}\mathbf{t} \\
6.55^{* * *}\end{array}$} & \multirow{3}{*}{$\frac{\mathbf{d f}}{39}$} & \multirow{3}{*}{$\begin{array}{l}\text { Sig. (2-tailed) } \\
0.000\end{array}$} \\
\hline \multirow{2}{*}{ ART } & \multirow{2}{*}{$\begin{array}{l}\text { Dominant hand - } \\
\text { Non-dominant hand }\end{array}$} & & & & & \\
\hline & & 17.60 & 2.02 & & & \\
\hline \multirow[b]{2}{*}{ VRT } & \multirow{2}{*}{$\begin{array}{l}\text { Dominant hand - } \\
\text { Non-dominant hand }\end{array}$} & 18.65 & 1.76 & \multirow{2}{*}{$7.05 * *$} & \multirow{2}{*}{39} & \multirow{2}{*}{0.000} \\
\hline & & 20.43 & 1.88 & & & \\
\hline
\end{tabular}

Significance level at $39 \mathrm{df}$ at $* 0.05$ level $=2.023$ and at $* * 0.01$ level $=2.708$

Table: 2 of paired t-test of ART and VRT between dominant and non-dominant hand of university athletes and non-athletes together shows that ART dominant hand mean $=15.95 \mathrm{~ms}$ and $\mathrm{SD}=1.87 \mathrm{~ms}$, and non-dominant hand mean $=17.60 \mathrm{~ms}$ and $\mathrm{SD}=$ $2.02 \mathrm{~ms}, \mathrm{t}_{(39)}=6.55$ and $\mathrm{p}=0.000,(2$-tailed); whereas VRT dominant hand mean $=18.65 \mathrm{~ms}$ and $\mathrm{SD}=1.76$ $\mathrm{ms}$, and non-dominant hand mean $=20.43 \mathrm{~ms}$ and SD
$=1.88 \mathrm{~ms}, \mathrm{t}_{(39)}=7.05$ and $\mathrm{p}=0.000,(2$-tailed $)$; both are statistically significant as tabulated value of $t(0.01)(39)$ $=2.708 \& \mathrm{p}<0.01$. It has been observed that the result dominant hand of ART and VRT was significantly lower than that of non-dominant hand university athletes and non-athletes together. This confirms that, in terms of ART and VRT, both groups of dominant hands are faster.

Table-3: Independent t-test of ART and VRT of hands between athletes and non-athletes

\begin{tabular}{|c|c|c|c|c|c|c|c|c|}
\hline \multirow{2}{*}{\multicolumn{2}{|c|}{ Parameter }} & \multicolumn{2}{|l|}{ Athletes } & \multicolumn{2}{|c|}{ Non-Athletes } & \multicolumn{3}{|c|}{ Independent t-test } \\
\hline & & Mean(ms) & $\mathbf{S D}(\mathrm{ms})$ & $\operatorname{Mean}(\mathrm{ms})$ & SD(ms) & $\mathbf{t}$ & df & Sig. (2-tailed) \\
\hline \multirow{2}{*}{ ART } & $\begin{array}{l}\text { Dominant } \\
\text { hand }\end{array}$ & 15.25 & 1.80 & 16.65 & 1.69 & $2.53 *$ & 38 & 0.015 \\
\hline & $\begin{array}{l}\text { Non-dominant } \\
\text { hand }\end{array}$ & 16.90 & 1.86 & 18.30 & 1.98 & $2.31 *$ & 38 & 0.026 \\
\hline \multirow{2}{*}{ VRT } & $\begin{array}{l}\text { Dominant } \\
\text { hand }\end{array}$ & 18.05 & 1.64 & 19.25 & 1.71 & $2.26^{*}$ & 38 & 0.029 \\
\hline & $\begin{array}{l}\text { Non-dominant } \\
\text { hand }\end{array}$ & 19.80 & 1.82 & 21.05 & 1.76 & $2.20 *$ & 38 & 0.033 \\
\hline
\end{tabular}

Significance level at $38 \mathrm{df}$ at $* 0.05$ level $=2.024$ and at $* * 0.01$ level $=2.721$

Table: 3 of independent sample t-test of ART and VRT of dominant and non-dominant hands between university athletes and non-athletes shows that ART of dominant hand athletes mean $=15.25 \mathrm{~ms}$ and $\mathrm{SD}=1.80$ $\mathrm{ms}$, and non-athletes mean $=16.65 \mathrm{~ms}$ and $\mathrm{SD}=1.69$ $\mathrm{ms}, \mathrm{t}_{(38)}=2.53$ and $\mathrm{p}=0.015$, (2-tailed); and nondominant hand athletes mean $=16.90 \mathrm{~ms}$ and $\mathrm{SD}=1.86$ $\mathrm{ms}$, and non-athletes mean $=18.30 \mathrm{~ms}$ and $\mathrm{SD}=1.98$ ms, $\mathrm{t}_{(38)}=2.31$ and $\mathrm{p}=0.026$, (2-tailed); Here ART of dominant and non-dominant hands is statistically significant as tabulated value of $\mathrm{t}(0.05)(38)=2.024 \&$ $\mathrm{p}<0.05$. According to VRT of dominant hand athletes mean $=18.05 \mathrm{~ms}$ and $\mathrm{SD}=1.64 \mathrm{~ms}$, and non-athletes mean $=19.25 \mathrm{~ms}$ and $\mathrm{SD}=1.71 \mathrm{~ms}, \mathrm{t}_{(38)}=2.26$ and $\mathrm{p}=$ 0.029, (2-tailed); and non-dominant hand athletes mean $=19.80 \mathrm{~ms}$ and $\mathrm{SD}=1.82 \mathrm{~ms}$, and non-athletes mean $=$ 
Md. Hamidur Rahman \& Muhammad Shahidul Islam., J Adv Sport Phys Edu, Mar, 2021; 4(3): 24-29

$21.05 \mathrm{~ms}$ and $\mathrm{SD}=1.76 \mathrm{~ms}, \mathrm{t}_{(38)}=2.20$ and $\mathrm{p}=0.033$, (2-tailed). VRT is also statistically significant as tabulated value of $\mathrm{t}(0.05)(38)=2.024 \& \mathrm{p}<0.05$. Finally, table 3 result shows that ART and VRT, in respect of dominant and non-dominant hands, athletes took the upper hand over the non-athletes.

\section{DISCUSSION}

In the present study, the table 1 result shows that athletes and non-athletes groups ART was significantly lower than that of VRT, so both groups in ART was faster than the VRT. This finding is similar to the studies done by [28] they confirmed that in a simple reaction time task auditory reaction time is faster as compared to the visual reaction time. An auditory stimulus to reach the brain only takes 8-10 milliseconds [29], but a visual stimulus takes 20-40 milliseconds [30]. For this reason, auditory stimulus reaches the cortex faster than the visual stimulus. Another study has confirmed that visual stimuli are longer than auditory stimuli [31]. Researchers [32] studied 104 elite male soccer players and they determined there were significant differences between the audio and visual reaction times and ART were better than the VRT. In similar studies done by [1], they noticed that ART was superior as compared to VRT of male basketball players. A study was carried out by [33] has concluded that the ART is faster than the VRT in medical students. Our findings acknowledge the early studies and suggest that the earlier the stimulus enters the motor cortex, the quicker the response time to the stimulus would be.

Table 2 observed that the dominant hand of ART and VRT was significantly lower than nondominant hand athletes and non-athletes together. This confirms that the dominant hand was found faster than the non-dominant hand in terms of ART and VRT. The present study related to literature highlights that control of the hands is contralateral, such that left hemisphere controls the right hand and the right hemisphere controls the left hand [34]. However, right-handedness is the most common form, and it is estimated that around $90 \%$ of the human population is right-handed [35]. Further studies done by [36] used student t-test between hands of football and tennis players and the result shows that between the two groups, the difference between right- and left-hand reaction time. Researchers [37] show that reaction time of the dominant hand is faster as compared to the non-dominant hand. Other studies of light and sound between athletes and sedentary group and finally the result shows that significant difference in right and left-hand reaction time and also result goes to meaningful favor of athletes [38]. Among university women athletes and sedentary women, strong hand is faster than that of their weak hand in respect of simple choice visual reaction time [39]. All findings are similar to that of the present study. On the contrary, the reaction time of the dominant and non-dominant hands was not consistent with hemisphere processing theory. On simple reaction time task of university students they do not find any consistent difference between the dominant and nondominant hands [40]. These statements confirm and extend neither of the findings and they recommending that none of the hemifield effects between the dominant and non-dominant hands on both simple and choice reaction time tasks [41].

In our study table 1 found that an auditory stimulus was faster than the visual stimulus consequently the table 2 proved that the dominant hand of ART and VRT performed better than that of the nondominant hand. Now, these results have found a new literature lacuna, if and when the non-dominant hand in games and sports is faster than that of the dominant hand.

According to table 3, the ART and VRT result shows that there was a statistically significant difference between university athletes and non-athletes both in dominant and non-dominant hands. ART and VRT in both hands of university athletes took the upper hand over the non-athletes group. Results supporting our study were also observed by [42] they concluded that auditory and visual reaction time was significantly less in both dominant hand and non-dominant hands of basketball players than the healthy controls. For about 130 years, researchers accepted for mean auditory reaction times being $140-160$ milliseconds $(160 \mathrm{~ms})$ and visual reaction times being 180-200 milliseconds (190ms) [43-45]. Previous studies suggested that nonathletes auditory, visual and multiple reaction times were found worse than the different sport branches athletes [46]. A further study conducted by [47] found that non-sport sedentary had higher average milliseconds in auditory and visual reaction time than racket athletes. The visual reaction time of dominant and non-dominant hands of badminton players was shorter than the healthy males who lived a sedentary lifestyle [48]. A study done on the simple reaction time of 94 right-handed healthy males and results shows that significant difference between right hand and left-hand values, and right hand is faster than left hand for auditory and visual reaction time [49].

\section{CONCLUSIONS}

Based on the findings of this investigation, researchers conclude that the athletes and non-athletes groups' auditory reaction time (ART) is faster as compared to the visual reaction time (VRT). Athletes and non-athletes, both groups together, the dominant hand was superior in quickness than the non-dominant hand. However, auditory reaction time (ART) and visual reaction time (VRT) of dominant and nondominant hands of university athletes took the upper hand over the non-athletes group. 
Md. Hamidur Rahman \& Muhammad Shahidul Islam., J Adv Sport Phys Edu, Mar, 2021; 4(3): 24-29

FUNDING

This research received no external funding.

\section{ACKNOWLEDGEMENT}

The authors thank the subjects of study.

\section{CONFLICTS OF INTEREST}

The authors declare no conflict of interest.

\section{REFERENCES}

1. Ghuntla, T. P., Mehta, H. B., Gokhale, P. A., \& Shah, C. J. (2014). A comparison and importance of auditory and visual reaction time in basketball players. Saudi Journal of Sports Medicine, 14(1), 35-38.

2. Batra, A., Vyas, S., Gupta, J., Gupta, K., \& Hada, R. (2014). A comparative study between young and elderly indian males on audio-visual reaction time. Ind. J. Sci. Res. and Tech, 2(1) 25-29.

3. Luce, R. D. (2008). Response Times: Their Role in Inferring Elementary Mental Organization. New York: Oxford University Press.

4. Donders, F. C. (1868). On the speed of mental processes. Translated by W. G. Koster, 1969. Acta Psychologica, 30, 412-431.

5. Singer, R. N., Murphey, M., \& Tennant, L. K. (1993). Handbook of research on sport psychology. New York: Macmillan.

6. Badau, D., Baydil, B., \& Badau, A. (2018). Differences among three measures of reaction time based on hand laterality in individual sports. Sports, 6(45), 1-6.

7. Mohan, M., Thombre, D. P., Das, A. K., Subramanian, N., \& Chandrasekar, S. (1984). Reaction time in clinical diabetes mellitus. Indian J Physiol Pharmacol, 28(4), 311-314.

8. Malathi, A. R., Parulkar, V. G., Dhavale, H. S., \& Pinto, C. (1990). A preliminary study of reaction time in schizophrenics. Indian Journal of Physiology and Pharmacology, 34(1), 54-56.

9. Hoyes Beehler, P. J., \& Kamen, G. (1986). Fractionated reaction time responses to auditory and Electrocutaneous Stimuli. Research Quarterly for Exercise and Sport, 57(4), 298-307.

10. Pancar, Z., Özdal, M., Pancar, S., \& Biçer, M. (2016). Investigation of visual and auditory simple reaction time of 11-18 aged youth. European Journal of Physical Education and Sport Science, 2(4), 145-152, doi:10.5281/zenodo.164029.Journal of Basic and Applied Medical Research, 3(4), 304307.

11. Devi, B. S., \& Madhuri N, K. (2017). Comparative study of visual and auditory reaction times on the basis of gender and physical activity levels of medical students. MedPulse International Journal of Physiology, 4(1), 4-6, doi.org/10.26611/103411.

12. Caspersen, C. J., Powell, K. E., \& Christenson, G. M. (1985). Physical activity, exercise, and physical fitness: definitions and distinctions for healthrelated research. Public Health Reports (Washington, D.C.: 1974), 100(2), 126-131.

13. Islam, M. S., Rahman, M. H., \& De, A. (2020). Exercising with face mask during the pandemic: A qualitative analysis. Saudi Journal of Sports Medicine, 20(3), 59-63, DOI:10.4103/sjsm.sjsm_37_20.

14. Hascelik, Z., Basgöze, O., Türker, K., Narman, S., \& Ozker, R. (1989). The effects of physical training on physical fitness tests and auditory and visual reaction times of volleyball players. The Journal of Sports Medicine and Physical Fitness, 29(3), 234-239.

15. Ng, A. W., \& Chan, A. H. (2012). Finger Response Times to Visual, Auditory and Tactile Modality Stimuli. Proceedings of the International Multi Conference of Engineers and Computer Scientist. Hong Kong.

16. Fozard, J. L., Vercruyssen, M., Reynolds, S. L., Hancock, P. A., \& Quilter, R. E. (1994). Age differences and changes in reaction time: The baltimore longitudinal study of aging. Journal of Gerontology, 49(4), 179-189.

17. Collardeau, M., Brisswalter, J., \& Audiffren, M. (2001). Effects of a prolonged run on simple reaction time of well trained runners. Perceptual and Motor Skills, 93(3), 679-689, doi.org/10.2466/pms.2001.93.3.679.

18. Fox, E. L., Bowers, R. W., Foss, M. L., \& Cerit, M. (2012). Beden Eğitimi ve Sporun Fizyolojik Temelleri. Ankara: Ankara: Spor Yayınevi ve Kitabevi.

19. Mokha, R., Kaur, G., \& Sidhu, L. S. (1992). Effect of training on the reaction time of indian female hockey players. The Journal of Sports Medicine and Physical Fitness, 32(4), 428-431.

20. Baruwal, H. B. (1983). Significance and some facts on reaction time in sports. Vyayam Vidnyan, 16(4), 3-7.

21. Zamfir, M. V. (2017). Verbal and non-verbal communication in sport environment. Marathon, IX(1), 99-106.

22. Pedersen, P. M., Miloch, K. S., \& Laucella, P. C. (2007). Strategic Sports Communication. Champaign, IL: Human Kinetics.

23. Islam, M. S., \& Kundu, B. (2020). Association of dribbling with linear and non-linear sprints in young soccer players of bangladesh. International Journal of Medicine and Public Health, 10(3), 100103.

24. Islam, M. S. (2018). Relationship of abdominal muscle endurance with selected anthropometric measurements in soccer players. International Journal of Physiology, Nutrition and Physical Education, 3(2), 1088-1090.

25. Rahman, M. H., Chanda, S., \& Reza, M. N. (2020). Comparison of simple choice visual reaction time between athlete and sedentary university women 
Md. Hamidur Rahman \& Muhammad Shahidul Islam., J Adv Sport Phys Edu, Mar, 2021; 4(3): 24-29

students. European Journal of Physical Education and Sport Science, 6(4), 1-8.

26. Rahman, M. H., \& Islam, M. S. (2020). Stretching and flexibility: A range of motion for games and sports. European Journal of Physical Education and Sport Science, 6(8), 22-36.

27. Medisystems medical eqipements. (n.d.). Retrieved $1020, \quad 2020, \quad$ from https://medisystemsindia.com/product/audiovisual-reaction-timer/.

28. Shelton, J., \& Kumar, G. P. (2010). Comparison between auditory and visual simple reaction time. Neuroscience \& Medicine, 1, 30-32.

29. Kemp, B. J. (1973). Reaction time of young and elderly subjects in relation to perceptual deprivation and signal-on versus signal-off condition. Developmental Psychology, 8(2), 268272.

30. Marshall, W. H., Talbot, S. A., \& Ades, H. W. (1943). Cortical response of the anaesthesized cat to gross photic and electrical afferent stimulation. Journal of Nerophysiology, 6, 1-15.

31. Pain, M. T., \& Hibbs, A. (2007). Sprint starts and the minimum auditory reaction time. Journal of Sports Sciences, 25(1), 79-86.

32. Şenel, Ö., \& Eroğlu, H. (2006). Correlation between reaction time and speed in elite soccer players. J Exerc Sci Fit, 4(2), 126-130.

33. Jain, A., Bansal, R., Kumar, A., \& Singh, K. (2015). A comparative study of visual and auditory reaction times on the basis of gender and physical activity levels of medical first year students. International Journal of Applied and Basic Medical Research, 5(2), 124-127.

34. Annett, M. (1981). The right shift theory of handedness and developmental language problems. Annals of Dyslexia, 31, 103-121, doi:10.1007/BF02658604.

35. Scharoun, S. M., \& Bryden, P. J. (2014). Hand preference, performance abilities, and hand selection in children. Frontiers in Psychology, 5(82), 1-15.

36. Koç, H., Kaya, M., Saritaş, N., \& Çoksevim, B. (2006). Comparement of Some Physical and Physiological Parametres of Football Players and Tennis Players. Sağlık Bilimleri Dergisi (Journal of Health Sciences), 15(3), 161-167.

37. Kerr, M., Mingay, R., \& Elithorn, A. (1963). Cerebral dominance in reaction time responses. British Journal of Psychology, 54(4), 325-336.

38. Özmerdivenl, R., Öztürk, A., \& Karacabey, K. (2004). Sporcu ve sedanterlerin reaksiyon zamanlarının karşılaştırılması ve egzersizin bazı fizyolojik parametrelere etkisi. Doğu Anadolu Bölgesi Araştırmaları Dergisi, 2(2), 82-87.

39. Rahman, M. H., Chanda, S., \& Reza, M. N. (2020). Comparison of simple choice visual reaction time between athlete and sedentary university women students. European Journal of Physical Education and Sport Science, 6(4), 1-8.

40. Gignac, G. E., \& Vernon, P. A. (2004). Reaction time and the dominant and non-dominant hands: An extension of Hick's Law. Personality and Individual Differences, 36, 733-739.

41. Bisiach, E., Mini, M., Sterzi, R., \& Vallar, G. (1982). Hemispheric lateralization of the decisional stage in choice reaction times to visual unstructured stimuli. Cortex, 18(2), 191-197.

42. Palashikar, S. G., Waghmare, P. P., \& Mundewadi, S. A. (2014). Comparative study of auditory reaction time, visual reaction time and agility in basketball players and healthy controls. IndianJournal of Basic and Applied Medical Research, 3(4), 304-307.

43. Galton, F. (1890). Exhibition of instruments (1) for testing perception of differences of tint, and (2) for determining reaction-time. The Journal of the Anthropological Institute of Great Britain and Ireland, 19, 27-29.

44. Fieandt, K. V., Huhtala, A., Kullberg, P., \& Saarl, K. (1956). Personal tempo and phenomenal time at different age levels. Reports from the Psychological Institute, No. 2, University of Helsinki.

45. Welford, A. T. (1980). Choice reaction time: basic concepts. In: Welford AT, editor. Reaction Times. New York: Academic Press, 73-128.

46. Atan, T., \& Akyol, P. (2014). Reaction times of different branch athletes and correlationbetween reaction time parameters. Procedia-Social and Behavioral Sciences, 116, 2886-2889.

47. Kaplan, D. S., Yıldırım, C., Akcan, F., Özdal, M., Abakay, Z., \& Bağçeci, A. M. (2019). The investigation of visual and auditory reaction time in racket sports by skills and sedentary. European Journal of Physical Education and Sport Science, 5(5), 11-18.

48. Dube, S. P., Mungal, S. U., \& Kulkarni, M. B. (2015). Simple visual reaction time in badminton players: a comparative study. National Journal of Physiology, Pharmacy \& Pharmacology, 5(1), 1820.

49. Kalyanshetti, S. B., \& Vastrad, B. C. (2013). Effect of handedness on visual, auditory and cutaneous reaction times in normal subjects. Al Ameen J Med Sc, 6(3), 278-280. 